\title{
The Effect of Probiotic and Omega-3 Supplements on Total Oxidant and Total Antioxidant Levels in Experimental Colitis
}

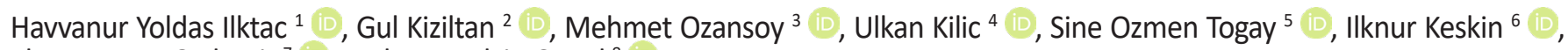 \\ Ekrem Musa Ozdemir ${ }^{7}$ (D) Mehmet Yalcin Gunal $^{8}$ \\ ${ }^{1}$ Istanbul Medeniyet University, Faculty of Health Sciences, Department of Nutrition and Dietetics, Istanbul, Turkey. \\ ${ }^{2}$ Baskent University, Faculty of Health Sciences, Department of Nutrition and Dietetics, Ankara, Turkey. \\ ${ }^{3}$ Bahcesehir University, Faculty of Medicine, Department of Physiology, Istanbul, Turkey. \\ ${ }^{4}$ University of Health Sciences, Faculty of Medicine, Department of Medical Biology, Istanbul, Turkey. \\ ${ }^{5}$ Bursa Uludag University, Faculty of Agriculture, Department of Food Engineering, Bursa, Turkey. \\ ${ }^{6}$ Istanbul Medipol University, Faculty of Medicine, Department of Histology and Embriology, Istanbul, Turkey. \\ ${ }^{7}$ Istanbul Medipol University, Istanbul Medipol University Medical Research Center, Istanbul, Turkey. \\ ${ }^{8}$ Alanya Alaaddin Keykubat University, Faculty of Medicine, Department of Physiology, Alanya, Turkey.
}

Correspondence Author: Havvanur Yoldas Ilktac

E-mail: havvanuryoldas55@hotmail.com, havvanur.yoldas@medeniyet.edu.tr

Received: 20.01.2021 Accepted: 14.04.2021

\begin{abstract}
Objective: Treatment of inflammatory bowel disease (IBD) usually involves medical therapy. For this reason, it is recommended to seek alternative treatment methods such as nutritional therapy. The aim of the study is to evaluate the effects of probiotics and omega- 3 fatty acids on total oxidant and total antioxidant levels in an experimental colitis model.

Methods: Mice were randomly divided into five groups ( $n=10 /$ group) as healthy group, colitis group, group treated with probiotics (VSL\#3), group treated with omega-3 (w-3), and group treated with both probiotics and omega-3. To induce experimental colitis, $200 \mathrm{mg} / \mathrm{kg}$ dinitrobenzene sulfonic acid (DNBS) + 30\% ethanol combination was rectally administered to anesthetized mice. Total oxidant (TOS) and total antioxidant (TAS) levels were measured at the tissue level.

Results: Lower concentrations of TOS were observed in the probiotics groups (2.11 $\pm 0.23 \mathrm{mmol} \mathrm{H} 2 \mathrm{O} 2 \mathrm{Eq} / \mathrm{L})$, probiotics+omega-3 (2.56 \pm 1.18 $\mathrm{mmol} \mathrm{H} 2 \mathrm{O} 2 \mathrm{Eq} / \mathrm{L})$, and omega-3 (3.02 $\pm 1.88 \mathrm{mmol} \mathrm{H} 2 \mathrm{O} 2 \mathrm{Eq} / \mathrm{L})$ groups compared to the colitis group (3.11 $\pm 0.91 \mathrm{mmol} \mathrm{H} 2 \mathrm{O} 2 \mathrm{Eq} / \mathrm{L})(\mathrm{p}>0.05)$. Higher TOS and TAS level were observed in the control colitis group compared to other groups; however, the differences were not statistically significant.

Conclusion: Our findings showed that TAS and TOS levels were positively affected by the use of probiotic supplements in IBD. It was determined that using w-3 alone was ineffective in decreasing TOS levels. Studies with higher dosages and longer treatment periods are needed to better observe the effects of nutritional supplements on TOS and TAS parameters in inflammatory bowel diseases.
\end{abstract}

Keywords: Probiotics, omega-3 fatty acids, total antioxidant level, total oxidant level, colitis, inflammatory bowel diseases

\section{INTRODUCTION}

Inflammatory bowel disease (IBD) is a systemic disease with an unknown etiology, believed to arise from the interaction between genetic, environmental and intestinal immune factors (1). It is suggested that IBD is caused by an imbalance between pro-oxidant and antioxidant mechanisms (2). Excessive production of oxygen-derived free radicals creates a negative effect on various biological systems (3). Inflammation is directly related to oxidative stress. Conditions such as the increase in the production of free radicals, the inefficacy of the antioxidant defense system cause oxidative stress by disturbing this balance $(4,5)$. Oxidative stress is defined as a condition that causes damage to the organism as a result of the deterioration of the balance between oxidants and antioxidants. It can also occur as a result of an increase in the amount of reactive hydrogen and nitrogen species (RONS) formed by the activation of phagocytic cells. $(6,7)$. Substances produced by oxidative damage are defined as oxidative stress markers. Malondialdehyde (MDA), the final product of lipid peroxidation, is one of these substances $(8,9)$. Lipid peroxidation caused by hydroxyl and superoxide radicals is the key reaction that damages the intestinal mucosa (10). Various animal models and human studies reveal an inverse relationship between antioxidant (AOX) enzyme $(11,12)$ and MDA levels (13). There are many markers used for the evaluation of oxidative stress and antioxidant status (14). However, measuring these markers separately is both 
time-consuming and expensive (15). Consequently, in recent years total oxidant level (TOS) (16) and total antioxidant level (TAS) have been measured (17).

Treatment of inflammatory bowel disease (IBD) usually involves medical therapy and aggressive therapeutic applications are recommended to control inflammation (18). The drugs used can pose a risk to the patient as it can trigger the development of opportunistic infections (19). As a result, it is recommended to seek alternative treatment methods such as nutritional therapy or nutritional support (20). Probiotics are living microorganisms that have a health benefit to the host when taken in sufficient amounts. It was shown that probiotics, especially bifidobacteria, affect cytokine release and reduce mucosal inflammation in IBD animal models $(21,22)$. It is known that $w-3$ fatty acids, which are among long-chain fatty acids, have strong antiinflammatory properties (20). The aim of this study is to evaluate the effects of probiotics and $w-3$ fatty acids on total oxidant and total antioxidant levels in an experimental colitis model.

\section{METHODS}

\subsection{General Plan of the Study}

In this study, BALB/c mouse ( $n=50$, aged 6-8 weeks) with weights ranging from 20-30 g were used. The mice were given ad libitum fresh drinking water and standard laboratory chow, in a room where the temperature was $21 \pm 2^{\circ} C^{\prime}$. Their natural night-day cycle was protected. Mice were randomly divided into five groups ( $n=10 /$ group) as healthy (non-colitis) group, colitis group, group treated with probiotics (colitis induced mice treated with probiotics), group treated with omega-3 (colitis induced mice treated with $\mathrm{w}-3$ ), group treated with probiotics+omega-3 (colitis induced mice treated with both probiotics and $w-3$ ). Some of the mice died during the study due to diarrhea, aspiration, etc. Analysis was conducted on 29 remaining mice. Ethical Committee approval was taken from Istanbul Medipol University Animal Experiments Local Ethical Committee dated 05/12/2014, numbered 38328770/83.

\subsection{Experimental Colitis Model}

The mice were not given any food, they were only given free access to water 24 hours before the experiment. Anesthesia was intraperitoneally injected at a dose of $80 \mathrm{mg} / \mathrm{kg}$ ketamine hydrochloride (Ketalar, Parke Davis ve Eczacibasi, Istanbul) and $10 \mathrm{mg} / \mathrm{kg}$ xylazine hydrochloride (Rompun, Bayer HealthCare). A mixture of $2-6 \mathrm{mg}(200 \mathrm{mg} / \mathrm{kg})$ of dinitrobenzene sulfonic acid (DNBS) $+30 \%$ ethanol was given rectally to mice under anesthesia to create experimental colitis, except for the healthy group (23). Phosphate-buffered saline (PBS) was given to the healthy group under the same conditions. Figure 1 shows the protocol of DNBS-induced colitis.

\subsection{Nutritional Supplementation}

Ten days after colitis induction, the groups received probiotics, w-3, probiotic plus w-3, or PBS alone (control non-colitis and control colitis groups) for ten days (day 1423). The VSL\#3 probiotic mixture was prepared daily for ten days, dissolved in $200 \mathrm{~mL}$ drinking water and administered intragastrically to the probiotic and probiotic plus w-3 groups. VSL\#3 is a mixture of one billion CFU of freeze-dried probiotics in one capsule, consisting of eight bacterial strains including three strains of bifidobacteria (B longum, B infantis, and $B$ breve), four strains of lactobacilli ( $L$ acidophilus, $L$ paracasei, L delbrueckii subsp. bulgaricus, and L plantarum), and Streptococcus salivarius subsp. thermophilus (Sigma-Tau Pharmaceuticals (Gaithersburg, MD, USA). Additionally, mice in the $w-3$ and probiotic plus $w-3$ groups received a $300 \mathrm{mg} /$ kg dose of $w-3$ fatty acids intragastrically for ten days. The $w-3$ is a soft gel form of $w-3$ containing 504 mg EPA and 378 mg DHA per capsule (Omega 950, Solgar, Turkey, Inc).

\subsection{Collection of Samples}

Mice were sacrificed by cervical dislocation, the rectum was removed with median laparotomy and gently cleaned with normal saline. The longitudinally divided colon segment was maintained at $-80^{\circ} \mathrm{C}$ for determination of total oxidant and total antioxidant levels.

\subsection{Tissue Homogenization}

Colon material, obtained by the sacrification of experimental animals, was weighed, and RIPA (Santa Cruz) solution was added per sample for lysis at 2 times the mass observed in the weighing; the added RIPA solution also contains a protease inhibitor cocktail. In the next stage, the tissues were subjected to mechanical decomposition manually on the ice. Then samples were centrifuged for 30 minutes at 14,000 rpm at $+4^{\circ} \mathrm{C}$, and supernatants were collected.

\subsection{Determination of Antioxidant Capacity and Oxidative Stress}

TAS and TOS levels of colon tissue homogenates were automatically measured by using the Chromate Manager 4300 (Palm City, USA) analyzer. Absorbance levels of dianicidyl radicals formed as a result of the Fenton reaction were determined in TAS measurement. The antioxidant effect in the samples was then calculated for Trolox equivalent ( $\mathrm{mmol}$ equiv/L) (Rel Assay Diagnostics, Gaziantep, Turkey). In TOS measurement, in the presence of oxidants, the absorbance caused by the ferric ions that consist of the ferrous ionodianicide complex was determined. Calibration was carried out with hydrogen peroxide, and TOS levels were determined as mmol $\mathrm{H}_{2} \mathrm{O}_{2} \mathrm{Eq} / \mathrm{L}$ (Rel Assay Diagnostics, Gaziantep, Turkey). 


\subsection{Statistical analysis}

Quantitative data obtained from mice were tabulated by calculating their mean (mean) and standard deviations (SD). Qualitative data was given as number $(n)$. The distributions of the groups were evaluated by one-sample KolmogorovSmirnov test from non-parametric tests. Groups that showed normal distribution were evaluated with one-way ANOVA (post hoc Tukey's HSD test for binary comparisons). Statistical analyses were carried out using the SPSS 15.0 package program, $p<0.05$ expressed statistical significance.

\section{RESULTS}

As shown in Table 1, lower concentrations of TOS ( $p>0.05)$ were observed in the probiotics $\left(2.11 \pm 0.23 \mathrm{mmol} \mathrm{H}_{2} \mathrm{O}_{2}\right.$ $\mathrm{Eq} / \mathrm{L})$, probiotics $+\mathrm{w}-3\left(2.56 \pm 1.18 \mathrm{mmol} \mathrm{H}_{2} \mathrm{O}_{2} \mathrm{Eq} / \mathrm{L}\right)$, and $\mathrm{w}-3$ (3.02 $\pm 1.88 \mathrm{mmol} \mathrm{H}_{2} \mathrm{O}_{2} \mathrm{Eq} / \mathrm{L}$ ) groups compared to the colitis group (3.11 $\pm 0.91 \mathrm{mmol}_{2} \mathrm{O}_{2} \mathrm{Eq} / \mathrm{L}$ ). The lowest TAS level was determined in the probiotic group $\left(1.49 \pm 0.32 \mathrm{mmol}_{2} \mathrm{O}_{2}\right.$ $\mathrm{Eq} / \mathrm{L})$. Higher TOS and TAS level were observed in the control colitis group compared to the other groups. However, the differences were not statistically significant.

Table 1. TOS and TAS levels of different groups

\begin{tabular}{|l|c|c|}
\hline & TOS & TAS \\
\cline { 2 - 3 } & (mmol H $\left.\mathrm{O}_{2} \mathrm{Eq} / \mathrm{L}\right)$ & (mmolTrolox Eq/L) \\
\cline { 2 - 3 } & Mean \pm SD & Mean \pm SD \\
\hline Healthy Group $(n=6)$ & $2.89 \pm 1.04$ & $1.53 \pm 0.55$ \\
\hline Colitis Group $(\mathrm{n}=6)$ & $3.11 \pm 0.91$ & $1.92 \pm 0.48$ \\
\hline Probiotics Group $(\mathrm{n}=5)$ & $2.11 \pm 0.23$ & $1.49 \pm 0.32$ \\
\hline Omega-3 Group $(\mathrm{n}=6)$ & $3.02 \pm 1.88$ & $1.85 \pm 0.33$ \\
\hline Probiotic+Omega-3 Group $(\mathrm{n}=6)$ & $2.56 \pm 1.18$ & $1.50 \pm 0.43$ \\
\hline $\mathrm{p}^{+}$ & 0.101 & 0.264 \\
\hline
\end{tabular}

TOS: total oxidant status, TAS: total antioxidant status, mmol: millimole, $\mathrm{H}_{2} \mathrm{O}_{2}$ : Hydrogen Peroxide, Eq: equivalent, L: Litre

\section{DISCUSSION}

Oxidative stress occurs as a result of excessive oxidant radical formation or due to the lack of antioxidant defense molecules and has an active role in the pathogenesis of IBD $(24,25)$. An increase in MDA tissue level indicates an increase in free oxygen radicals (26). In this study, we found the highest TOS level and the lowest TAS level in the colitis group. Similarly, it has been reported that serum TOS levels increase in experimental colitis models $(14,27)$. One study reported that TOS was significantly reduced in IBD patients compared to healthy controls (25). Probiotics suppress bacterial translocation and reduce the number of enterobacteria and enterococci in the ileum and cecum. In a study examining the protective properties of kefir in an experimental colitis model created in rats, it was found that the group receiving kefir had statistically significant lower MDA levels compared to the group that did not receive kefir (28). The effect of B. infantis strain was examined in rats with colitis; it was found that the MDA level was significantly lower compared to the colitis group that did not receive probiotic support (29). In accordance with our study, Mane J et al. (30) showed that the group supported by probiotics had lower level of oxidative stress. Some studies have found that probiotic supplementation did not affect oxidative stress level $(31,32)$ just like w-3 supplementation (33). Morampudi et al. (34) reported that $\mathrm{w}-3$ supplementation reduces oxidative stress. In a meta-analysis on inflammatory bowel diseases, the contribution of $\mathbf{w}-3$ supplementation to the oxidation state was controversial. The same meta-analysis reported that w-3 fatty acids were safe but ineffective for the remission of ulcerative colitis (UC) and Crohn's disease (33). In this study, the highest and lowest TOS levels were determined in colitis and probiotic + omega-3 groups, respectively. Decreased TOS levels in groups receiving probiotic supplements showed that probiotics have an important role in oxidant capacity. The use of $w-3$ together with a probiotic supplement was found to be more effective than using $\mathrm{w}-3$ alone in reducing TOS levels.

Oxidative stress causes damage by affecting biomolecules and organs in the organism. In normal physiological conditions, there is a balance between oxidant and antioxidant mechanisms (24). It was reported that antioxidant enzyme activities (catalase, glutathione, peroxidase, etc.) and glutathione levels, one of the endogenous antioxidants, were decreased in IBD (35). Decreased antioxidant enzyme levels were also observed in previous studies with IBD patients $(10,36)$. Studies showed that TAS was significantly reduced in IBD patients compared to healthy controls $(25,37)$. On the contrary, D'Odorico et. al (38) stated that individuals with the disease had higher antioxidant enzyme levels compared to healthy individuals. In this study, similar to the study of D'Odorico et. al (38) it was determined that the colitis group had the highest TAS level $(p=0.264)$. It is thought that the reason for the high level of TAS in the colitis group was increased functioning of cellular antioxidant systems resulting in increased oxidant production.

Probiotics and $w-3$ are among the current treatment choices for IBD. It has been reported that probiotics have anti-inflammatory effects in the gut $(39,40)$ and increase antioxidant capacity (39) but there is no sufficient evidence for $w$-3 fatty acids $(41,42)$. In our study, TAS levels were found to be higher in groups that received probiotic or omega-3 supplements compared to the healthy group. The TAS level of the $w-3$ group was higher compared to the healthy group, but the difference was not statistically significant. Similar to our study, in a study examining the effects of omega supplementation on antioxidant enzyme levels in inflammatory bowel diseases, it was reported that the patient group had higher antioxidant enzyme levels compared to the healthy control group but the difference was not statistically significant (43). Initially, we thought that the lowest TAS level would be in the colitis group but on the contrary, the highest TAS level was found in this group. This suggests that both the dose used and the duration of support may be insufficient 
in the supplementation groups. In this study, we measured TOS to determine oxidant capacity and TAS to determine antioxidant capacity using intestinal tissues. However one of the limitations of our study was that oxidative damage markers and antioxidant molecules were not determined to evaluate oxidative stress and antioxidant status.

\section{CONCLUSION}

It has been suggested that probiotics are effective in decreasing total oxidant capacity and $w-3$ in increasing total antioxidant capacity. The use of $w-3$ together with a probiotic supplement was found to be more effective than $w-3$ use alone in reducing TOS levels. In addition, it has been observed that the combined use of omega and probiotic supplements is more effective in increasing TAS levels than using omega or probiotics alone. Studies with higher dosages and longer treatment periods are required for IBD to observe the effects on TOS and TAS parameters better. It seems that the immune cells, oxidant, and antioxidant systems of IBD patients have not been evaluated in detail in the literature. These mechanisms have not yet been clearly resolved and more research is needed. We suggest that it would be useful to examine the status of TAS and TOS together with oxidative damage markers and antioxidant molecules in future studies.

Financial Disclose: This study was produced from the PhD thesis and it was supported by the Scientific and Technological Research Council of Turkey (TUBITAK) as the project number 115 S679 on $22 / 06 / 2015$.

\section{REFERENCES}

[1] Baumgart DC, Carding SR. Inflammatory bowel disease: cause and immunobiology. Lancet 2007; 369(9573): 1627-1640. doi: 10.1016/S0140-6736(07)60750-8

[2] Sands BE. From symptom to diagnosis: clinical distinctions among various forms of intestinal inflammation. Gastroenterology 2004; 126(6): 1518-32. doi: 10.1053/j. gastro.2004.02.072

[3] Sarma A, Rahaman Mallick A, Ghosh A. Free radicals and their role in different clinical conditions: an overview. Int J Pharma Sci Res. 2010; 1(3): 185-192.

[4] Satsangi J, Silverberg M, Vermeire S, Colombel J-F. Satsangi J, Silverberg MS, Vermeire S, Colombel JF. The Montreal classification of inflammatory bowel disease: controversies, consensus, and implications. Gut 2006; 55(6): 749-753. doi: 10.1136/gut.2005.082909

[5] Buyukuslu N, Yigitbasi T. Reactive oxygen species and oxidative stress in obesity. MÜSBED 2015; 5(3): 197-203. doi: 10.5455/ musbed.201.506.04061607 (Turkish)

[6] Aghdassi E, Wendland BE, Steinhart AH, Wolman SL, Jeejeebhoy K, Allard JP. Antioxidant vitamin supplementation in Crohn's disease decreases oxidative stress. a randomized controlled trial. Am J Gastroenterol. 2003; 98(2): 348-53. doi: 10.1111/j.1572-0241.2003.07226.x

[7] Catarzi S, Favilli F, Romagnoli C, Marcucci T, Picariello L, Tonelli F, Vincenzini MT, lantomasi T. Oxidative state and IL-6 production in intestinal myofibroblasts of Crohn's disease patients. Inflamm Bowel Dis. 2011; 17(8): 1674-1684. doi: 10.1002/ibd.21552

[8] Keshavarzian A, Banan A, Farhadi A, Komanduri S, Mutlu E, Zhang Y, Fields ZJ. Increases in free radicals and cytoskeletal protein oxidation and nitration in the colon of patients with inflammatory bowel disease. Gut 2003; 52(5): 720-728.

[9] Krzystek-Korpacka M, Neubauer K, Berdowska I, Zielinski B, Paradowski L, Gamian A. Impaired erythrocyte antioxidant defense in active inflammatory bowel disease: impact of anemia and treatment. Inflamm Bowel Dis. 2010; 16(9): 14671475. doi: 10.1002/ibd.21234

[10] Pinto MAS, Lopes MS-MS, Bastos STO, Reigada CLL, Dantas RF, Neto JCB, Luna SA, Madi K, Nunes T, Zaltman C. Does active Crohn's disease have decreased intestinal antioxidant capacity? J Crohns Colitis. 2013; 7(9): e358-366. doi: 10.1016/j. crohns.2013.02.010

[11] Breganó JW, Dichi JB, Barbosa DS, El Kadri MZ, Matsuo T, Rodrigues MA, Cecchini R, Dichi I. Decreased total antioxidant capacity in plasma, but not tissue, in experimental colitis. Dig Dis Sci. 2009; 54(4): 751-757. doi: 10.1007/s10620.008.0439-z

[12] Kruidenier L, Kuiper I, Van Duijn W, Mieremet-Ooms MAC, van Hogezand RA, Lamers CBHW, Verspaget HW. Imbalanced secondary mucosal antioxidant response in inflammatory bowel disease. J Pathol. 2003; 201(1): 17-27. doi: 10.1002/ path.1408

[13] Kruidenier L, Kuiper I, Lamers CBHW, Verspaget HW. Intestinal oxidative damage in inflammatory bowel disease: semiquantification, localization, and association with mucosal antioxidants. J Pathol. 2003; 201(1): 28-36. doi: 10.1002/ path.1409

[14] Özgün E, Özgün GS, Eskiocak S, Yalçin Ö, Gökmen SS. Deneysel kolitte L-karnitinin serum paraoksonaz, arilesteraz ve laktonaz aktivitelerine ve oksidatif duruma etkisi. Turkish J Biochem. 2013; 38(2): 145-153. doi: 10.5505/tjb.2013.29292 (Turkish)

[15] Del Rio D, Stewart AJ, Pellegrini N. A review of recent studies on malondialdehyde as toxic molecule and biological marker of oxidative stress. Nutr Metab Cardiovasc Dis. 2005; 15(4): 316-328. doi: 10.1016/j.numecd.2005.05.003

[16] Erel O. A new automated colorimetric method for measuring total oxidant status. Clin Biochem. 2005; 38(12): 1103-1111. doi: 10.1016/j.clinbiochem.2005.08.008

[17] Erel O. A novel automated direct measurement method for total antioxidant capacity using a new generation, more stable ABTS radical cation. Clin Biochem. 2004; 37(4): 277-285. doi: 10.1016/j.clinbiochem.2003.11.015

[18] Cosnes J, Gower-Rousseau C, Seksik P, Cortot A. Epidemiology and natural history of inflammatory bowel diseases. Gastroenterology 2011; 140(6): 1785-94. doi: 10.1053/j. gastro.2011.01.055

[19] Biancone L, Calabrese E, Petruzziello C, Pallone F. Treatment with biologic therapies and the risk of cancer in patients with IBD. Nat Clin Pract Gastroenterol Hepatol. 2007; 4(2): 78-91. doi: $10.1038 /$ ncpgasthep0695

[20] Calder PC. The relationship between the fatty acid composition of immune cells and their function. Prostaglandins Leukot Essent Fatty Acids. 2008; 79(3-5): 101-108. doi: 10.1016/j. plefa.2008.09.016

[21] Bassaganya-Riera J, Viladomiu M, Pedragosa M, De Simone C, Carbo A, Shaykhutdinov R, Jobin C, Arthur JC, Corl BA, Vogel H, Storr M, Hontecillas R. Probiotic bacteria produce conjugated linoleic acid locally in the gut that targets macrophage PPAR $\gamma$ 
to suppress colitis. PLoS One 2012;7(2):e31238. doi: 10.1371/ journal.pone.0031238

[22] Ersan LY, Topçuoğlu E. Microbiological and some physico-chemical properties of probiotic yogurt enriched with almond milk. Bursa Uludag Üniv Ziraat Fak Derg. 2019; 33(2): 321-339. (Turkish)

[23] Martín R, Chain F, Miquel S, Lu J, Gratadoux J-J, Sokol H, Verdu EF, Bercik P, Bermudez-Humaran LG, Langella P. The commensal bacterium Faecalibacterium prausnitzii is protective in DNBS-induced chronic moderate and severe colitis models. Inflamm Bowel Dis. 2014; 20(3): 417-430. doi: 10.1097/01. MIB.000.044.0815.76627.64

[24] Iborra M, Moret I, Rausell F, Bastida G, Aguas M, Cerrillo E, Nos $\mathrm{P}$, Beltran B. Role of oxidative stress and antioxidant enzymes in Crohn's disease. Biochem Soc Trans. 2011; 39(4): 1102-6. doi: 10.1042/BST0391102

[25] Yuksel MD, Ates I, Kaplan M, Arikan M, Ozin Y, Mesut Z, Topcuoglu C, Kayacetimn E. Is oxidative stress associated with activation and pathogenesis of inflammatory bowel disease? J Med Biochem. 2017; 36(4): 341-348. doi: 10.1515/jomb-2017-0013

[26] Matsuda H, Fujiyama Y, Andoh A, Ushijima T, Kajinami T, Bamba T. Characterization of antibody responses against rectal mucosa-associated bacterial flora in patients with ulcerative colitis. J Gastroenterol Hepatol. 2000; 15(1): 61-68. doi: 10.1046/j.1440-1746.2000.02045.x

[27] Bitiren M, Karakilcik AZ, Zerin M, Ozardali I, Selek S, Nazligül Y, Ozgonul A, Musa D, Uzunkoy A. Protective effects of selenium and vitamin $\mathrm{E}$ combination on experimental colitis in blood plasma and colon of rats. Biol Trace Elem Res. 2010; 136(1): 87-95. doi: 10.1007/s12011.009.8518-3

[28] Özkan N. Sıçanlarda trinitrobenzene sulphonic acid (TNBS) ile uyarılan kolit modelinde kefirin koruyucu etkinliğinin araştırılması. Süleyman Demirel Üniversitesi Tıp Fakültesi iç Hastalıkları Anabilim Dalı Uzmanlık Tezi, Isparta, 2008. (Turkish)

[29] Osman N, Adawi D, Molin G, Ahrne S, Berggren A, Jeppsson B. Bifidobacterium infantis strains with and without a combination of oligofructose and inulin (OFI) attenuate inflammation in DSS-induced colitis in rats. BMC Gastroenterol. 2006; 6: 31 doi: doi: 10.1186/1471-230X-6-31

[30] Mañé J, Lorén V, Pedrosa E, Ojanguren I, Xaus J, Cabré E, Domenech E, Gassul MA. Lactobacillus fermentum CECT 5716 prevents and reverts intestinal damage on TNBS-induced colitis in mice. Inflamm Bowel Dis. 2009; 15(8): 1155-1163. doi: $10.1002 /$ ibd.20908

[31] Mazloom Z, Yousefinejad A, Dabbaghmanesh MH. Effect of probiotics on lipid profile, glycemic control, insulin action, oxidative stress, and inflammatory markers in patients with type 2 diabetes: a clinical trial. Iran J Med Sci. 2013; 38(1): 38-43.

[32] Lamprecht $M$, Bogner $S$, Schippinger $G$, Steinbauer $K$, Fankhauser F, Hallstroem S, Schuetz B, Greilberger JF. Probiotic supplementation affects markers of intestinal barrier, oxidation, and inflammation in trained men; a randomized, double-blinded, placebo-controlled trial. J Int Soc Sports Nutr. 2012; 9(1): 45. doi: 10.1186/1550-2783-9-45
[33] Turner D, Zlotkin SH, Shah PS, Griffiths AM. Omega 3 fatty acids (fish oil) for maintenance of remission in Crohn's disease. Cochrane database Syst Rev. 2007; (2): CD006320. doi: 10.1002/14651858.CD006320.pub2

[34] Morampudi V, Bhinder G, Wu X, Dai C, Sham HP, Vallance BA, Jacobson K. DNBS/TNBS colitis models: providing insights into inflammatory bowel disease and effects of dietary fat. J Vis Exp. 2014; 84: e51297-e51297. doi: 10.3791/51297

[35] Nieto N, Torres MI, Fernández MI, Girón MD, Ríos A, Suárez MD, Gil A. Experimental ulcerative colitis impairs antioxidant defense system in rat intestine. Dig Dis Sci. 2000; 45(9): 18201827. doi: $10.1023 / a: 100.556 .5708038$

[36] Maor I, Rainis T, Lanir A, Lavy A. Oxidative stress, inflammation and neutrophil superoxide release in patients with Crohn's disease: distinction between active and non-active disease. Dig Dis Sci. 2008; 53(8): 2208-2214. doi: 10.1007/ s10620.007.0141-6

[37] Koutroubakis I, Malliaraki N, Dimoulios P, Karmiris K, Castanas E, Kouroumalis E. Decreased total and corrected antioxidant capacity in patients with inflammatory bowel disease. Dig Dis Sci. 2004; 49: 1433-1437. doi: 10.1023/B:DDAS.000.004.2242.22898.d9

[38] D'Odorico A, Bortolan S, Cardin R, D'Inca' R, Martines D, Ferronato A, Sturniola GC. Reduced plasma antioxidant concentrations and increased oxidative DNA damage in inflammatory bowel disease. Scand J Gastroenterol. 2001; 36(12): 1289-1294. doi: 10.1080/003.655.201317097146

[39] Peran L, Camuesco D, Comalada M, Nieto A, Concha A, DiazRopero MP, Olivares M, Xaus J, Zarzuelo A, Galvez J. Preventative effects of a probiotic, Lactobacillus salivarius ssp. salivarius, in the TNBS model of rat colitis. World J Gastroenterol. 2005; 11(33): 5185-5192. doi: 10.3748/wjg.v11.i33.5185

[40] Peran L, Camuesco D, Comalada M, Bailon E, Henriksson A, Xaus J, Galvez J. A comparative study of the preventative effects exerted by three probiotics, Bifidobacterium lactis, Lactobacillus casei and Lactobacillus acidophilus, in the TNBS model of rat colitis. J Appl Microbiol. 2007; 103(4): 836-844. doi: 10.1111/j.1365-2672.2007.03302.x

[41] Turner D, Shah PS, Steinhart AH, Zlotkin S, Griffiths AM. Maintenance of remission in inflammatory bowel disease using omega-3 fatty acids (fish oil): a systematic review and meta-analyses. Inflamm Bowel Dis. 2011; 17(1): 336-345. doi: $10.1002 /$ ibd. 21374

[42] Lev-Tzion R, Griffiths AM, Leder O, Turner D. Omega 3 fatty acids (fish oil) for maintenance of remission in Crohn's disease. Cochrane database Syst Rev. 2014; 2: CD006320. doi: 10.1002/14651858.CD006320.pub4

[43] Barbosa DS, Cecchini R, El Kadri MZ, Rodríguez MAM, Burini RC, Dichi I. Decreased oxidative stress in patients with ulcerative colitis supplemented with fish oil omega-3 fatty acids. Nutrition 2003; 19(10): 837-842. doi: 10.1016/s08999007(03)00162-x

How to cite this article: Yoldas Ilktac H, Kiziltan G, Ozansoy M, Kilic U, Ozmen Togay S, Keskin I, Ozdemir EM, GUNAL MY . The Effect of Probiotic and Omega-3 Supplements on Total Oxidant and Total Antioxidant Levels in Experimental Colitis. Clin Exp Health Sci 2021; 11: 362-366. DOI: 10.33808/clinexphealthsci.865058 